\title{
Computational identification of microRNAs in Anatid herpesvirus 1 genome
}

\author{
Jun Xiang ${ }^{1}$, Anchun Cheng ${ }^{1,2,3^{*}}$, Mingshu Wang ${ }^{1,2,3^{*}}$, Shunchuan Zhang ${ }^{1}$, Dekang Zhu ${ }^{2,3}$, Renyong Jia ${ }^{1,2,3}$, \\ Shun Chen ${ }^{1,2,3}$, Yi Zhou ${ }^{2}$, Xiaoyu Wang ${ }^{3}$ and Xiaoyue Chen ${ }^{2,3}$
}

\begin{abstract}
Background: MicroRNAs (miRNAs) are a group of short ( $22 \mathrm{nt})$ noncoding RNAs that specifically regulate gene expression at the post-transcriptional level. miRNA precursors (pre-miRNAs), which are imperfect stem loop structures of $\sim 70 \mathrm{nt}$, are processed into mature miRNAs by cellular RNases III. To date, thousands of miRNAs have been identified in different organisms. Several viruses have been reported to encode miRNAs.

Findings: Here, we extended the analysis of miRNA-encoding potential to the Anatid herpesvirus 1 (AHV-1). Using computational approaches, we found that AHV-1 putatively encodes 12 mature miRNAs. We then compared the 12 mature miRNAs candidates with the all known miRNAs of the herpesvirus family. Interestingly, the "seed sequences" (nt 2 to 8) of 2 miRNAs were predicted to have the high conservation in position and/or sequence with the 2 miRNAs of Marek's disease virus type 1 (MDV-1). Additionally, we searched the targets from viral mRNAs.

Conclusions: Using computational approaches, we found that AHV-1 putatively encodes 12 mature miRNAs and 2 miRNAs have the high conservation with the 2 miRNAs of MDV-1. The result suggested that AHV-1 and MDV-1 should have closed evolutionary relation, which provides a valuable evidence of classification of AHV-1. Additionally, seven viral gene targets were found, which suggested that AHV-1 miRNAs could affect its own gene expression.
\end{abstract}

Keywords: Anatid herpesvirus 1, microRNA, Conservation, Computational analyses

\section{Findings}

MicroRNAs (miRNAs) are noncoding small RNA molecules with important regulatory functions in expression of target genes [1,2]. The miRNAs are about 19 to 25 nucleotides (nt) long. They are firstly transcribed as long primary miRNAs, which are processed into 60-70 nt miRNA precursor (pre-miRNA) by nuclear RNase III Drosha [3]. Pre-miRNA is then exported to the cytoplasm by the export factor Exportin 5 and further cleaved into $\sim 22$ nt duplexes [4]. Mature miRNAs regulate protein-coding gene expression via the RNA silencing machinery, typically by forming imperfect duplexes with target messenger RNAs (mRNAs).

\footnotetext{
* Correspondence: chenganchun@vip.163.com; mshwang@163.com ${ }^{1}$ Institute of Preventive Veterinary Medicine, Sichuan Agricultural University, Wenjiang, Chengdu city, Sichuan 611130, People's Republic of China ${ }^{2}$ Avian Disease Research Center, College of Veterinary Medicine of Sichuan Agricultural University, 46 Xinkang Road, Ya'an, Sichuan 625014, People's Republic of China

Full list of author information is available at the end of the article
}

To date, thousands of miRNAs have been identified in different organisms [5]. The discovery of miRNAs encoded by DNA viruses suggests that viruses have evolved to exploit RNA silencing for regulation of the expression of their own genes, host genes, or both [6]. Most viral miRNAs (vmiRNAs) have been identified by cDNA cloning of small RNAs from virus-infected cells [7-10], whereas others have been identified following computational prediction and hybridization analysis [10-12]. Experimental screening of vmiRNAs via high-throughput sequencing of large numbers of cDNA clones from infected cells is technically challenging, time consuming and could be incomplete, given that viral gene expression can have highly constrained tissue-, time-, and replication state-specific patterns [12]. Of the vmiRNAs identified so far, most are encoded by viruses in the herpesvirus family, containing $\alpha$ [13-16], $\beta$ [17], $\gamma$ subfamily $[8,9,18]$. AHV-1, an unassigned virus in the family Herpesviridae, can induce duck viral enteritis in waterfowl of the family Anatidae. To query whether this

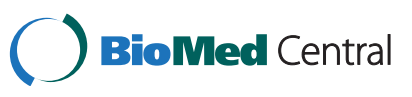




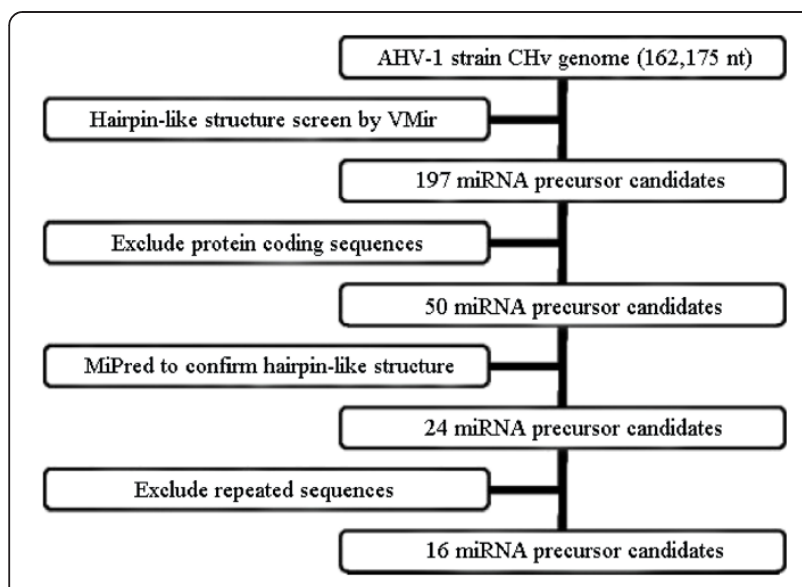

Figure 1 Flowchart of the AHV-1 miRNA prediction procedure.

strategy is also employed by AHV-1 or not, we have analyzed putative miRNA-encoding capacity of AHV-1.

The AHV-1 miRNA prediction was performed using the complete genome sequence of AHV-1 strain $\mathrm{CHv}$ (JQ647509) [19]. The genome size is 162,175 nt. Figure 1 shows a flowchart of the computational prediction process. Briefly, the viral genome was scanned for hairpin-structured miRNA precursors using VMir Analyzer program [20,21]. 197 sequences with potential hairpinlike structures were extracted as candidate miRNA precursors. Then candidates within or antisense to protein-coding regions were removed according to the NCBI genome annotations. 50 precursors were further identified using MiPred program (http://www.bioinf.seu.edu. $\mathrm{cn} / \mathrm{miRNA} /$ ) and the sequences with lower minimum free energy (equivalent or below $-25 \mathrm{kcal} \mathrm{mol}^{-1}$ ) were remained, subsequently, the remained 24 real pre-microRNA sequences were conducted BLASTn searching against itself to remove repeated sequences. Finally, 16 sequences were selected as miRNA precursors candidates. At the last step, the mature sequences were predicted by Bayes-SVM-MiRNA web server v1.0 (http:// wotan.wistar.upenn. edu/BayesSVMmiRNAfind/). After that, 12 mature sequences were predicted with $21 \mathrm{nt}$ in length (Table 1) and the secondary structure of premiRNAs were shown in Figure 2.

In order to investigate whether the AHV-1 miRNAs predicted are conserved in other herpesviruses, each of the 12 putative mature AHV-1 miRNA candidates was compared with the all known miRNAs of the herpesvirus family independently in database (http://www.sanger.ac.uk/Software/ $\mathrm{Rfam} / \mathrm{mirna} /$ ). Interestingly, the "seed sequences" (nt 2 to 8) of 2 miRNAs were predicted to have the high conservation with the 2 miRNAs of MDV-1 (Table 2). The genomic positions of the 2 miRNAs encoded by MDV-1 are proximal to the latencyassociated transcript region. The vmiRNAs have generally been reported to lack sequence conservation across different viral species [10], with the exception of the primate polyomaviruses [11]. But among closed viral species, they could showed conservation in position and/or sequence. Jurak et al identified 16 and 17 miRNAs expressed by herpes simplex viruses 1 and 2 (HSV-1 and -2), respectively. The genomic positions of most miRNAs encoded by these two viruses are within or proximal to the latency associated transcript region. Nine miRNAs are conserved in position and/or sequence, particularly in the seed region, between these two viruses [16]. Additional, Waidner et al reported the genome locations, but not microRNA sequences, are conserved among four avian herpesviruses, infectious laryngotracheitis virus (ILTV) and herpesvirus of turkeys (HVT), as well as Marek's disease viruses (MDV-1 and MDV-2). Most are clustered in the repeats flanking the unique long region

Table 1 Sequences and genomic positions of putative AHV-1 miRNAs

\begin{tabular}{|c|c|c|c|}
\hline No. & $\begin{array}{l}\text { Predicted mature } \\
\text { miRNAsequence }\left(5^{\prime} \text { to } 3^{\prime}\right)\end{array}$ & $\begin{array}{l}\text { Position, } \\
\text { orientation }\end{array}$ & Location \\
\hline 1 & CUCCCUUGCUUUGACAUGUCC & $26325-26345,-$ & Within intergenic region between UL44 and UL45 \\
\hline 2 & UCGUUGGGCGGUUUCUUCGUG & 72302-72322, - & Within intergenic region between UL26 and UL27 \\
\hline 3 & UUCAAACGGAGGCGUUGUGCG & $72512-72532,+$ & Within intergenic region between UL26 and UL27 \\
\hline 4 & UUUCUGGGACCUCACCGCGGA & $79262-79282,+$ & Within intergenic region between UL22 and UL23 \\
\hline 5 & UAAGAACUGCUGGUACCUUGC & $112559-112579,+$ & Within intergenic region between UL4 and UL5 \\
\hline 6 & CAACGGAUGAACGUCGGCGCG & 112720-112740, - & Within intergenic region between UL4 and UL5 \\
\hline 7 & CAUGGGAACAUUUAACACCCC & $123128-123148,+$ & Within intergenic region between ICP22 and LORF2 \\
\hline 8 & UGGAUGGUUUGGAGACAGCUG & $125173-125193,+$ & Within intergenic region between ICP4 and ICP22 \\
\hline 9 & UAUGUUUUGCCCGGGCAAAUG & 132907-132927, + & Within intergenic region between US1 and ICP4 \\
\hline 10 & AAAUCUGGCGUUCGCACUCUG & 134522-134542, - & Within intergenic region between US1 and ICP4 \\
\hline 11 & AUUUCGGAGUGCGAAUAUGUG & 134586-134606, - & Within intergenic region between US1 and ICP4 \\
\hline 12 & GGUAGGUUGUUUGGAGAUUGC & $160321-160341,+$ & Within unique short terminal repeat region \\
\hline
\end{tabular}


(I/TRL), except in ILTV which lacks these repeats [14]. So the result suggested that AHV-1 and MDV-1 should have closed evolutionary relation, which provides a valuable evidence of classification of AHV-1. Meanwhile, the prevalence of microRNAs in the genomic repeat regions suggests that the latent infection in herpesviruses could be relevant to function of microRNA.

What is the function of the vmiRNA? In order to know whether the vmiRNA could modulate its own genes expression, we checked the 3'UTR of viral mRNAs that could perfectly complement with the "seed sequence" of vmiRNA. AHV-1-pre-miR-4 was predicted to target

Table 2 miRNA homologs expressed by AHV-1 and MDV-1

\begin{tabular}{|c|c|c|}
\hline Name & miRNA sequence ${ }^{a}$ & $\begin{array}{l}\text { No. of identical } \\
\text { nt/totalin seed } \\
\text { region (nt } \\
\text { positions 2-8) } \\
\end{array}$ \\
\hline AHV-1-pre-miR-7 & \multirow{2}{*}{$\begin{array}{l}\text {-CAUGGGAACAUU-UAACACCCC } \\
\text { GCAUGGAAACGUCCUGGGAAA- - } \\
* * * * *+^{* * *}+^{*}+*+\dagger^{*}\end{array}$} & \multirow{2}{*}{$5 / 7$} \\
\hline MDV-1-miR-M13 & & \\
\hline AHV-1-pre-miR-9 & \multirow{2}{*}{$\begin{array}{l}\text { UAUGUUUUGCCCGGGCAAAUG- } \\
\text { UCUGUUGUUCCGUAGUGUUCUC } \\
\text { U }^{* * * *} *^{* *} \quad t^{*}+\dagger \quad+\end{array}$} & \multirow[t]{2}{*}{$5 / 7$} \\
\hline MDV-1-miR-M6-5p & & \\
\hline
\end{tabular}

${ }^{a}$ Sequences of orthologous miRNAs expressed by AHV-1 and MDV-1 aligned using ClustalW2. The seed sequences are shown in boldface. Identical nucleotides and nucleotides with conserved target binding potential are indicated with * and $t$, respectively.
UL29 gene (DNA replication-recombination; binds single-stranded DNA) and US5 gene (unknown function). AHV-1-pre-miR-7 was predicted to target UL16 gene (capsid maturase). AHV-1-pre-miR-9 was predicted to target UL15B gene (DNA cleavage-encapsidation), UL45 (tegument/envelope protein), and US1 gene (immediateearly and late transrepressor protein). AHV-1-pre-miR12 was predicted to target UL45 gene and US7 gene (cell-cell spread). However, none of gene targets were found for the other vmiRNAs. Additionally, we wonder whether the putative vmiRNA could be used by AHV-1 to modulate host cell genes expression profiles. But so far genome of duck is in the process of being annotated and there is not available 3'UTR database of duck genes, so prediction can not be carried on.

Here, we introduced a concept that the AHV-1 genome could reasonably encode candidate pre-miRNAs. Studies are in progress to experimentally identify the putative vmiRNAs during AHV-1 infection.

\section{Competing interests}

The authors declare that they have no competing interests.

\section{Acknowledgements}

The research was supported by China 973 program(2011CB111606), National Natural Science Foundation of China (31072157), China Agricultural Research System (CARS-43-8), the Changjiang Scholars and Innovative Research Team of Sichuan Agricultural University (PCSIRT0848), and National science and technology support program for agriculture(2011BAD34B03). Anchun Cheng and Mingshu Wang are the corresponding authors at: Institute of Preventive 
Veterinary Medicine, Sichuan Agricultural University \& Key Laboratory of Animal Disease and Human Health of Sichuan Province, Sichuan Agricultural University, Wenjiang, Chengdu city, Sichuan, 611130, P.R. China \& Avian Disease Research Center, College of Veterinary Medicine of Sichuan Agricultural University, 46\# Xinkang Road, Yucheng district, Yaan 625014, P.R. China. Tel.: +86 835 2885774; fax: +86 835 2885774. E-mail address: chenganchun@vip.163.com. (A. Cheng); mshwang@163.com (M. Wang).

\section{Author details}

'Institute of Preventive Veterinary Medicine, Sichuan Agricultural University, Wenjiang, Chengdu city, Sichuan 611130, People's Republic of China. ${ }^{2}$ Avian Disease Research Center, College of Veterinary Medicine of Sichuan Agricultural University, 46 Xinkang Road, Ya'an, Sichuan 625014, People's Republic of China. ${ }^{3}$ Key Laboratory of Animal Disease and Human Health of Sichuan Province, Sichuan Agricultural University, Wenjiang, Chengdu city, Sichuan 611130, People's Republic of China.

\section{Authors' contributions}

JX carried out most of the data collection, data analysis and drafted the manuscript. ACC, MSW, SCZ, DKZ, RYJ, SC, YZ, XYW and XYC helped draft the manuscript. All authors read and approved the final manuscript.

Received: 4 June 2011 Accepted: 14 May 2012

Published: 14 May 2012

\section{References}

1. Ambros V: The functions of animal microRNAs. Nature 2004, 431:350-355.

2. Bartel DP: MicroRNAs: genomics, biogenesis, mechanism, and function. Cell 2004, 116:281-297.

3. Lee Y, Ahn C, Han J, Choi H, Kim J, Yim J, Lee J, Provost P, Radmark O, Kim $\mathrm{S}, \mathrm{Kim}$ VN: The nuclear RNase III Drosha initiates microRNA processing. Nature 2003, 425:415-419.

4. Zeng Y, Cullen BR: Structural requirements for pre-microRNAbinding and nuclear export by Exportin 5. Nucleic Acids Res 2004, 32:4776-4785.

5. Griffiths-Jones S: The microRNA registry. Nucleic Acids Res 2004, 32:109-111.

6. Sullivan CS, Ganem D: MicroRNAs and viral infection. Mol Cell 2005, 20:3-7.

7. Pfeffer S, Zavolan M, Gra"sser FA, Chien M, Russo JJ, Ju J, John B, Enright AJ, Marks D, Sander C, Tuschl T: Identification of virus-encoded microRNAs. Science 2004, 304:734-736.

8. Cai X, Lu S, Zhang Z, Gonzalez CM, Damania B, Cullen BR: Kaposi's sarcoma-associated herpesvirus expresses an array of viral microRNAs in latently infected cells. Proc Natl Acad Sci USA 2005, 102:5570-5575.

9. Samols MA, Hu J, Skalsky RL, Renne R: Cloning and identification of a microRNA cluster within the latency-associated region of Kaposi's sarcoma-associated herpesvirus. J Virol 2005, 79:9301-9305.

10. Pfeffer S, Sewer A, Lagos-Quintana M, Sheridan R, Sander C, Gra"sser FA, van Dyk LF, Ho CK, Shuman S, Chien M, Russo JJ, Ju J, Randall G, Lindenbach $B D$, Rice CM, Simon V, Ho DD, Zavolan M, Tuschl T: Identification of microRNAs of the herpesvirus family. Nat Methods 2005, 2:269-276.

11. Sullivan CS, Grundhoff AT, Tevethia S, Pipas JM, Ganem D: SV40-encoded microRNAs regulate viral gene expression and reduce susceptibility to cytotoxic T cells. Nature 2005, 435:682-686.

12. Cui C, Griffiths A, Li GL, Silva LM, Kramer MF, Gaasterland T, Wang XJ, Coen DM: Prediction and identification of Herpes Simplex Virus 1-encoded microRNAs. J Virol 2006, 80:5499-5508.

13. Morgan R, Anderson A, Bernberg E, Kamboj S, Huang E, Lagasse G, Isaacs G, Parcells M, Meyers BC, Green PJ, Burnside J: Sequence conservation and differential expression of Marek's disease virus microRNAs. J Virol 2008, $82: 12213-12220$

14. Waidner LA, Morgan RW, Anderson AS, Bernberg EL, Kamboj S, Garcia M, Riblet SM, Ouyang M, Isaacs GK, Markis M, Meyers BC, Green PJ, Burnside J: MicroRNAs of Gallid and Meleagrid herpesviruses show generally conserved genomic locations and are virus-specific. Virology 2009, 388:128-136.

15. Glazov EA, Horwood PF, Assavalapsakul W, Kongsuwan K, Mitchell RW, Mitter N, Mahony TJ: Characterization of microRNAs encoded by the bovine herpesvirus 1 genome. J Gen Virol 2010, 91:32-41.

16. Jurak I, Kramer MF, Mellor JC, van Lint AL, Roth FP, Knipe DM, Coen DM: Numerous conserved and divergent microRNAs expressed by herpes simplex viruses 1 and 2. J Virol 2010, 84:4659-4672.
17. Dunn W, Trang P, Zhong Q, Yang E, Belle CV, Liu FY: Human cytomegalovirus expresses novel microRNAs during productive viral infection. Cell Microbiol 2005, 7:1684-1695.

18. Cai X, Schafer A, Lu S, Bilello JP, Desrosiers RC, Edwards R, Raab-Traub N, Cullen BR: Epstein-Barr virus microRNAs are evolutionarily conserved and differentially expressed. PLoS Pathog 2006, 2:e23.

19. Ying Wu, Anchun Cheng, Mingshu Wang, Qiao Yang, Dekang Zhu, Renyong Jia, Shun Chen, Yi Zhou, Xiaoyu Wang, Xiaoyue Chen: Complete genomic sequence of chinese virulent duck enteritis virus. J Virol 2012, 86:5965.

20. Ullivan CS, Grundhoff A: Identification of Viral MicroRNAs. Methods Enzymol 2007, 427:1-23.

21. Grundhoff A, Sullivan CS, Ganem D: A combined computational and microarray-based approach identifies novel microRNAs encoded by human gamma-herpesviruses. RNA 2006, 12:733-750.

doi:10.1186/1743-422X-9-93

Cite this article as: Xiang et al: Computational identification of microRNAs in Anatid herpesvirus 1 genome. Virology Journal 2012 9:93.

\section{Submit your next manuscript to BioMed Central and take full advantage of:}

- Convenient online submission

- Thorough peer review

- No space constraints or color figure charges

- Immediate publication on acceptance

- Inclusion in PubMed, CAS, Scopus and Google Scholar

- Research which is freely available for redistribution

Submit your manuscript at www.biomedcentral.com/submit
() Biomed Central 